\title{
SIMPLE AND FAST DETERMINATION FOR GAMMA-HYDROXYBUTYRATE (GHB) IN URINE SAMPLE BY LLE AND GC-MS
}

\author{
André Valle de Bairros ${ }^{\mathrm{a}, *,(1)}$, Gustavo Andrade Ugalde $^{\mathrm{a}}$ and Mauricio Yonamine ${ }^{\mathrm{b}}$ \\ aNúcleo Aplicado à Toxicologia, Centro de Ciências da Saúde, Universidade Federal de Santa Maria, 97105-900 Santa Maria - \\ RS, Brasil \\ bDepartamento de Análises Clínicas e Toxicológicas, Faculdade de Ciências Farmacêuticas, Universidade de São Paulo, 05508-000 \\ São Paulo - SP, Brasil
}

Recebido em 25/06/2020; aceito em 05/08/2020; publicado na web em 21/09/2020

\begin{abstract}
Gamma-hydroxybutyrate (GHB) is a depressant of the central nervous system able to promote disinhibition, anterograde amnesia and its use is related to Drug-Facilitated Crimes (DFC). Urine is the biological matrix of choice for toxicological analysis in victims of rape and/or theft in suspected victims of DFC. The aim of this work was the development of a simple and ultra-fast methodology for GHB determination in urine samples using GC-MS. Briefly, $250 \mu \mathrm{L}$ of urine was pipetted in a vial and fortified with $10 \mu \mathrm{L}\left(250 \mu \mathrm{g} \mathrm{mL}{ }^{-1}\right)$ of internal standard GHB-d6. Then, the sample was acidified and submitted to extraction with ethyl acetate. After stirring, the material was taken to a microcentrifuge (1 minute at $5000 \mathrm{rpm}$ ). Then the dried residue was derivatized with BSTFA + 1\% TCMS for $10 \mathrm{~min}$ at $70{ }^{\circ} \mathrm{C}$ before injection. This method was successfully validated according UNODC and EMEA guidelines on bioanalytical method validation with limit of detection and limit of quantification were 0.25 and $0.50 \mu \mathrm{g} \mathrm{mL}^{-1}$, respectively. Considering all steps for GHB determination, this analytical procedure allows the fastest detection of GHB in urine samples when compared to literature allowing the analysis of DFC suspect cases or clinical when endogenous GHB requires to be measured.
\end{abstract}

Keywords: GHB; GC-MS; urine; LLE; simple and fast.

\section{INTRODUCTION}

Gamma-hydroxybutyrate (GHB) is a relatively simple molecular structure, with a $\mathrm{pKa}=4.72$ and is derived from the neurotransmitter GABA naturally produced by mammals. Its mechanism of action is based on its binding to a specific GABA receptor, as well as altering dopaminergic reception. ${ }^{1,2}$

GHB absorption is fast when administered orally, reaching maximum plasma concentration between 25 and 45 minutes without binding plasma proteins. GHB distribution is fast and its effects last around 1 to 4 hours depending on the dose. ${ }^{3}$ Multiple doses of GHB does not promote accumulation in the body and endogenous metabolites are excreted after metabolization. A small amount of unchanged GHB (1-5\% from administrated dose) is eliminated by urine, which it can be determined within 12 hours. After this period, GHB levels in urinary samples returns to endogenous baseline..$^{1,3,4}$

Disinhibition and increased sociability, anterograde amnesia and even increased libido are described as GHB effects. ${ }^{3,5-7}$ Beginning in the 1990s, GHB and its precursors (gamma-butyrolactone and 1,4-butanediol) began to be used in situations involving sexual abuse and other crimes due to the relatively easy obtaining and manufacture and rapidity of its effects. ${ }^{1,7}$

Urine is a biological sample that can be collected non-invasively in which most drugs and biotransformation products are generally excreted in high concentrations. In addition, urine allows for a relatively long period of detection and it is considered the biological matrix of choice for toxicological analysis in victims of rape and/or theft in suspected victims of DFC. ${ }^{9}$

In order to determinate GHB in urine samples for criminal cases, gas chromatography and liquid chromatography coupled to mass spectrometry (GC-MS and LC-MS, respectively) are considered gold standard equipments. However, considering the elevated cost and

*e-mail: andrebairros@yahoo.com.br availability of LC-MS, GC-MS is still more present in toxicology laboratories. Also, the possibility of reducing time-consuming sample processing steps, decreasing the number of reagents, and increasing the analytic speed and efficiency is always welcome in any forensic toxicology laboratory. So, we purpose a simple and fast methodology for GHB determination in urine samples using GC-MS to be applied in any laboratory.

\section{EXPERIMENTAL}

\section{Material and methods}

\section{Reagents and standards}

HPLC grade acetonitrile (ACN), methanol $(\mathrm{MeOH})$, ethyl acetate (EtOAc), chloroform $\left(\mathrm{CHCl}_{3}\right)$, dichloromethane (DCM) and isobutanol (i-BuOH) were obtained from Vetec ${ }^{\circledR}$ (Duque de Caxias, $\mathrm{RJ}$, Brazil). Hydrochloric acid $(\mathrm{HCl})$, sodium chloride $(\mathrm{NaCl})$ and anhydrous sodium sulfate $\left(\mathrm{Na}_{2} \mathrm{SO}_{4}\right)$ were purchased from Synth ${ }^{\circledR}$ (Diadema, SP, Brazil). GHB and GHB-D6 were purchased from Cerilliant $^{\circledR}$ (Round Rock, TX, USA). N,O-Bis(trimethylsilyl) trifluoroacetamide with trimethylchlorosilane (TCMS) (BSTFA + $1 \%$ TCMS) was purchased from Sigma-Aldrich ${ }^{\circledR}$ (St.Louis, MO, USA). Blank urine was obtained from volunteers who did not use the test substance and were collected from volunteers admitted to the Vila Serena treatment center for chemical dependence (São Paulo, SP, Brazil). Stock solutions were prepared with $\mathrm{MeOH}$ and stored at $-21^{\circ} \mathrm{C}$. Calibration and control solutions were prepared by successive dilutions of the stock standard solutions in methanol. Aliquots of calibration solutions were stored at $-20^{\circ} \mathrm{C}$ until use.

\section{Instrumentation}

The analyzes were performed using an Agilent 6850 Network GC System gas chromatograph coupled with an Agilent ${ }^{\circledR} 5975$ Series quadrupole mass seletive detector (MSD). The injections were done 
in splitless mode and the chromatographic separation was achieved with a capillary fused silica HP-5MS column (30 m x $0.25 \mathrm{~mm}$ x 0.1 film thickness) (Agilent, Santa Clara, CA, USA), using helium as a carrier gas at $1.0 \mathrm{~mL} \mathrm{~min}^{-1}$, in a constant flow mode. The column oven temperature program was as follows: first hold at $50{ }^{\circ} \mathrm{C}$ for 1 minute; incresase the temperature at a rate of $20^{\circ} \mathrm{C} \mathrm{min}^{-1}$ up to 120 ${ }^{\circ} \mathrm{C}$ (hold 1 minute); then at a rate of $30{ }^{\circ} \mathrm{C} \min ^{-1}$ up to $300{ }^{\circ} \mathrm{C}$. The total analysis time was $11.50 \mathrm{~min}$. The temperatures at the injection port and transfer line were $280{ }^{\circ} \mathrm{C}$. The analysis of the analytes by the MS was through electronic ionization (EI) $(70 \mathrm{eV})$ with selected ion monitoring (SIM) mode. The monitored ions were 233 (quantifier ion), 204 and $117 \mathrm{~m} / \mathrm{z} ; 239$ (quantifier ion), 210 and $123 \mathrm{~m} / \mathrm{z}$ for GHB and GHB-D6, respectively.

\section{Method development for determining GHB in urine samples}

\section{Optimization of GHB derivatization}

The GHB derivatization optimization study was carried out considering the incubation time and temperature using BSTFA + $1 \%$ TCMS as a derivatizing agent. The efficiency of the reaction was assessed through the total area under the conditions tested. The following parameters were studied: Derivatization in GC liner port (injection-port derivatization); Temperature $\left(70,80\right.$ and $\left.90{ }^{\circ} \mathrm{C}\right)$; Time $(5,10,20$ and 30 minutes $)$.

\section{Optimization of liquid-liquid extraction ( $L L E)$ for $G H B$}

Urine samples were fortified to a concentration of $10 \mu \mathrm{g} \mathrm{mL}^{-1}$ of GHB and it was evaluated extractor solvent: ethyl acetate, acetonitrile, iso-butyl alcohol, chloroform and a mixture of methanol:dichloromethane (20:80); $\mathrm{pH}$ of the biological matrix: 0,1 , 2, 3, 4 and 5; Extraction time: 10, 30, 60 and 600 seconds; Agitation: 1200, 1600, 2000 and 2400 rpm; Salting out effect: 0, 0.5 and 10\% $\mathrm{NaCl}\left(\mathrm{m} \mathrm{v}^{-1}\right)$ to the sample before the extraction procedure.

\section{Sample preparation}

A $250 \mu \mathrm{L}$ aliquot of urine was placed in a vial and fortified with $10 \mu \mathrm{L}\left(250 \mu \mathrm{g} \mathrm{mL}^{-1}\right)$ of internal standard GHB-D6. Sample was acidified with a solution of $3 \mathrm{~mol} \mathrm{~L}^{-1}$ of $\mathrm{HCl}$ until $\mathrm{pH} 2$ and then $500 \mu \mathrm{L}$ of ethyl acetate (organic phase) was added. The microtube was closed and stirred for 10 seconds at $2400 \mathrm{rpm}$ in a vortex. After stirring, the material was taken to a microcentrifuge (1 minute at $5000 \mathrm{rpm})$. Then $350 \mu \mathrm{L}$ of organic phase were removed and transferred to bottles containing anhydrous sodium sulfate. The supernatant resulting from this step was placed in a road with silanol groups deactivated for drying at $40^{\circ} \mathrm{C}$ under nitrogenous flow. Posteriorly, $35 \mu \mathrm{L}$ of BSTFA + $1 \%$ TCMS was added following vortex agitation and posterior incubation during 10 minutes at $70^{\circ} \mathrm{C}$. Subsequently, the vials were cooled to room temperature and $2 \mu \mathrm{L}$ aliquot was injected into the GC-MS. All steps for this procedure are showed in the Figure 1.

\section{Method validation of $G H B$}

The method was validated in urine samples according to Guidance for the Validation of Analytical Methodology and Calibration of Equipment used for Testing of Illicit Drugs in Seized Materials and Biological Specimens from United Nation Office on Drugs and Crime (UNODC) and Guideline on bioanalytical method validation from European Medicine Agency (EMEA). ${ }^{10,11}$

For the limit of detection (LOD) and limit of quantification (LOQ), a pool of urine samples from 20 individuals was used as blank sample. From this pool, different concentrations of GHB standard were evaluated in triplicates by fortification with known amounts of analytical standard, which chromatographic peaks were discounted from baseline endogenous GHB present. After obtaining the result of the triplicate, the same procedure was performed in sextuplicate to guarantee the LOD value. The response equivalent to three times signal:noise defined this parameter. The acceptance criteria for LOQ was the response within $\pm 20 \%$ of the expected value at the lower concentration. Linearity was assessed in six replicates with addition of GHB standard in blank urine samples, which the first point was LOQ $\left(0.5 ; 1.0 ; 2.5 ; 5 ; 10 ; 15\right.$ and $\left.20 \mu \mathrm{gL}^{-1}\right)$.

Selectivity/specificity was assessed using 13 potential interfering compounds (11-nor-9-carboxy-tetrahydrocannabinol, ethanol, paracetamol, acetylsalicylic acid, methylmalonic acid, succinic acid, beta-estradiol, caffeine, lorazepam, phenobarbital, benzocaine,

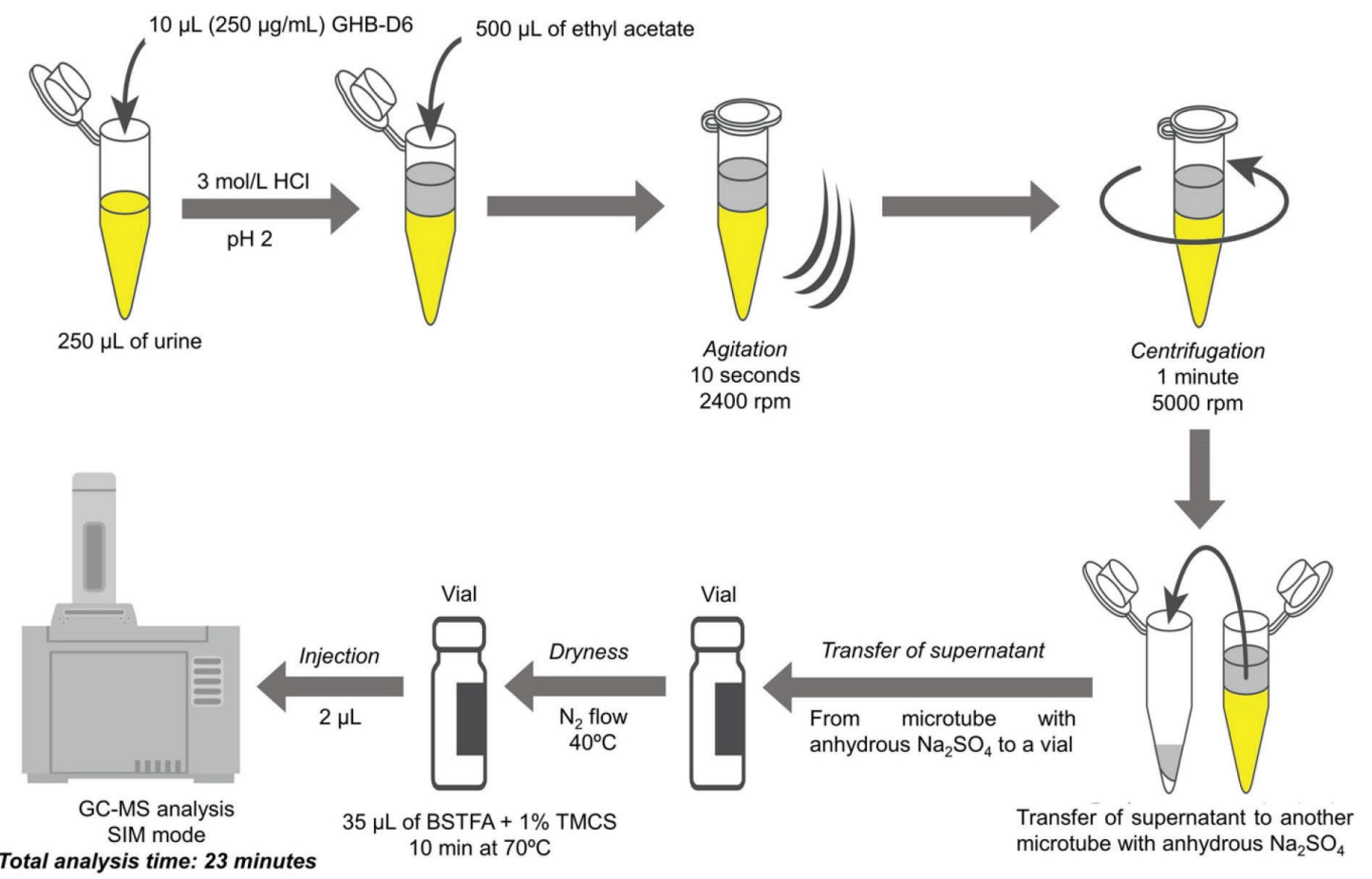

Figure 1. Step-by-step of purpose methodology for GHB determination in urine samples 
phenylpropanolamine, carisoprodol) at a concentration of $1000 \mathrm{ng} \mathrm{mL}^{-1}$, evaluating if these molecules can interfere with the GHB analysis following the extraction procedure developed in the present work. The acceptance criteria for this assay was the absence of interfering substances in the retention time of the analyte of interest and its respective internal standard.

Precision and accuracy of the studies were carried out by analyzing urine samples containing three known concentrations (1.5, 9.0 and $16 \mu \mathrm{g} \mathrm{mL}^{-1}$ ) on three consecutive days. The acceptance criteria for these assays was coefficient variation for the lower concentration controls must be lower than $20 \%$ and for the other control levels better than $15 \%$. Absolute recovery studies were performed by preparing two sets of urine samples. A set of samples (set A), which consists of three concentrations, where the first point with a concentration 3 times greater than the LOQ of the analyte $\left(1.5,9\right.$ and $\left.16 \mu \mathrm{g} \mathrm{mL}^{-1}\right)$. In the second set (set B), analytes were added to the samples with the same concentration used in the set A after the LLE procedure.

Absolute recovery was assessed by comparing the average response obtained for set A and the response for set B (100\%). UNODC Analytical Methods Validation Guide does not consider this factor as indicative for failing the test, if the other validation parameters achieve the desired purposes. ${ }^{10}$

Dilution integrity is a parameter that allows evaluation of samples with analyte levels above the calibration curve. It should be demonstrated by means of fortifing the matrix with analytes above the highest concentration of the curve and then diluting this sample with a blank matrix (at least five determinations per dilution factor). The acceptation criteria for this parameter is accuracy and precision within the set criteria, i.e. within $\pm 15 \%$ according to EMEA. ${ }^{11}$

\section{Application to real cases}

The study protocol was previously reviewed and approved by the Faculty of Pharmaceutical Sciences Ethics Committee, University of Sao Paulo, Brazil (Ethics Protocol Approval n ${ }^{\circ}$ CEP 98156). The quantification was based on the ratios of the ion peak areas of the GHB to the IS quantifying ion peak areas. The purpose of the analytical method was to apply in real cases that involved GHB intake, however during the 4-year period there were no suspected cases of chemical submission caused by GHB.

\section{RESULTS AND DISCUSSION}

GHB determination is considered a forensic challenge because it is an endogenous compound of low molecular weight, fast excretion and which has a structural similarity with other organic acids eliminated in the urine. In addition, the analysis of GHB by GC-MS is difficult due to the high polarity of this molecule. So, there is a need for the derivatization step to determine GHB by GC-MS.${ }^{12}$ Previously published papers opted for the conversion of GHB to GBL for analysis in GC-MS due to the possible interconversion in vitro, ${ }^{13-15}$ but GBL is still small sized and can be confused with other similar structures.

In this respect, derivatization with BSTFA $+1 \%$ TCMS is considered the best option due to its low cost, description of the derivatized in mass spectrometry libraries and handling facilities when compared to other derivatives. ${ }^{16,17}$ Derivatization is often carried out off-line after extraction. However, the possibility of performing this derivatization on-line could be a way of optimizing the timecomsumption of the method. To develop an ultra-fast methodology by GC-MS, derivatization in GC liner port (injection-port derivatization) was carried out after drying the extract. ${ }^{18}$

In this procedure, the derivatization occured in the gas phase, where the sample and the derivatization reagent were injected togheter into the liner port. So, before the splitless injection $35 \mu \mathrm{L}$ of BSTFA $+1 \%$ TCMS were added in the dried extract followed by vortexing for 30 seconds. After this $2 \mu \mathrm{L}$ were injected into the liner port at $280{ }^{\circ} \mathrm{C}$, where the derivatization step occurred. Initial results were promising with this approach. However, in a sequence of chromatographic injections, matrix interferents became more evident in the chromatograms, difficulting toxicological analysis and decreasing the useful life of the liner and the chromatographic column. So, incubation time and temperature were evaluated. The results indicated that $70^{\circ} \mathrm{C}$ for 10 minutes is the best derivatization process for this silylant agent, indicating a shorter time than established by the literature. ${ }^{16,17,19-27}$

Selected ion monitoring mode (SIM mode) was chosen because of increase of selectivity and decrease of the instrument's response to anything that interferes with the measurement, allowing the determination of a component in a complex chromatogram where the compounds do not resolve. ${ }^{28}$ Thus, SIM mode was chosen, considering there are many compounds with similar retention time as well as fragmentation pattern compared to GHB in urine samples. In fact, it is impractical to perform a GHB analysis on urinary matrix using GC-MS in SCAN mode.

For optimization of the GHB in urine samples by LLE, we evaluated polar solvents considering partition coefficient $(\log \mathrm{P}=-0.51)$ and ethyl acetate $(\log \mathrm{P}=0.71)$ obtained better results, as already demonstrated in literature. ${ }^{29}$ Isobutyl alcohol $(\log \mathrm{P}=0.8)$ and especially acetonitrile $(\log \mathrm{P}=-33)$ can form 2 phases in the urine samples. However, addition of GHB standard diluted with methanol in urinary matrices, even in very low volumes, promotes a system homogeneous, not allowing the separation of phases and consequently the extraction. An alternative procedure was the use of the mixture methanol: dichloromethane (20:80), however the results showed inefficiency of this mixture.

Similarly, different mixtures of ethyl acetate and acetonitrile were evaluated and there were no differences between the combinations 9:1 and 8:2 when compared with extracts exclusively from ethyl acetate. The composition ethyl acetate: acetonitrile (7:3) showed greater extractive capacity. However, the appearance of interfering matrix did not allow the continuation of this procedure. So, the chosen extractor solvent was ethyl acetate.

GHB has acidic characteristics $(\mathrm{pKa}=4.72)$ indicating that its extraction must be carried out in an acidic environment. The $\mathrm{pH}$ range used (0-5) demonstrated that $\mathrm{pH} 2$ was the best for the procedure, indicating that the molecule will be in the non-ionized form. When $\mathrm{pH}$ values are less than 2 convertion of GHB to GBL may occur through dehydration and consequently closing the aliphatic structure in cyclic, even in the absence of temperature. ${ }^{30,31}$ At a $\mathrm{pH}$ greater than 2, this molecule has greater ionized fractions, ${ }^{32}$ decreasing the extractive capacity of the solvent by LLE.

The addition of $\mathrm{NaCl}$ (salting out effect) and the frequency of agitation (rpm) do not influence the GHB extraction by LLE in urine samples, however the agitation time is essential. Although 1 and 10 minutes showed better results, we opted for a quick procedure ( 10 seconds) for the validation of the method, considering that the data indicated a low coefficient of variation with absolute area. The work focuses on the determination of GHB in urine quickly and simply.

All parameters of the method validation are in accordance with the UNODC guide. ${ }^{10}$ Linearity showed an equation of $\mathrm{y}=0.1144 \mathrm{X}-0.1247\left(\mathrm{R}^{2}=0.9932\right)$ and the heteroscedasticity phenomenon was not observed through the $\mathrm{F}$ test (Snedecor F distribution). No chromatographic interference was verified with the tested substances, demonstrating the specificity/selectivity of the proposed methodology. However, these results were only possible when SIM mode was applied, since countless molecules with similar characteristics to GHB are excreted in the urine samples and 
can interfere in the analysis. The other results of the validation are described in Table 1.

Table 1. Confidence parameters of the validated method for the determination of GHB in urine samples (sextuplicate for each point)

\begin{tabular}{ll}
\hline Confidence parameters & GHB \\
\hline
\end{tabular}

Absolute recovery (\%)

$\begin{array}{ll}\text { C1 } & 23.9 \\ \text { C2 } & 20.3 \\ \text { C3 } & 20.0\end{array}$

$\operatorname{LOD}\left(\mu \mathrm{g} \mathbf{m L}^{-1}\right)$

$\operatorname{LOQ}\left(\mu \mathrm{g} \mathrm{mL}^{-1}\right)$

Intra-day precision $(\mathrm{CV} \%)$

$\begin{array}{ll}\mathrm{C} 1 & 13.7 \\ \mathrm{C} 2 & 8.60 \\ \mathrm{C} 3 & 9.80\end{array}$

Inter-day precision (CV\%)

$\begin{array}{ll}\mathrm{C} 1 & 9.90 \\ \mathrm{C} 2 & 11.6 \\ \mathrm{C} 3 & 9.40\end{array}$

Accuracy (\%)

$\begin{array}{lc}\mathrm{C} 1 & 93.2 \\ \mathrm{C} 2 & 108.3 \\ \mathrm{C} 3 & 111.9\end{array}$

Dilution integrity

Precision $(\mathrm{CV} \%)$

10 times

Accuracy (\%)

10 times

101.1

$\mathrm{C} 1,1.5 \mu \mathrm{g} \mathrm{mL}^{-1}$; 2 , $9 \mu \mathrm{g} \mathrm{mL}-1$; C3, $16 \mu \mathrm{g} \mathrm{mL}-1$; LOD, limit of detection; $\mathrm{LOQ}$, limit of quantification; CV\%, coefficient of variation; GHB, gamma-

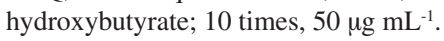

Due to the possibility of obtaining urine samples with high concentrations of GHB, dilution integrity was validated according to Guideline on bioanalytical method validation from European Medicine Agency. ${ }^{11}$ GHB standard was added in urine samples to a concentration of $50 \mu \mathrm{g} \mathrm{mL}^{-1}$ and the matrix was diluted $1 / 10$ with distilled water to obtain a final concentration of $5 \mu \mathrm{g} \mathrm{mL}$. Subsequently, the extraction process was carried out with a calibration curve. The result obtained was $5.05 \mu \mathrm{g} \mathrm{mL}^{-1}$ and the $\mathrm{CV} \%$ was less than $15 \%$. Figure 2 shows a typical chromatogram using SCAN and SIM mode obtained by the purpose methodology.

Unfortunately, it was not possible to apply this method in real samples from individuals until they had contact with GHB because no suspected cases reached our group as well as the São Paulo Scientific Police at the period which the methodology was developed. Therefore, it must be considered that GHB showed pharmacological effects like other central depressants drugs and rapid excretion (less than 12 hours in urine samples). These aspects could be responsible for the absence of real cases during the development of this method. ${ }^{33}$

According to the literature, the methodology described by Busardò et $a l .{ }^{33}$ is considered the fastest to analyze this molecule in biological fluids by GC-MS. This method is considered ultra-fast by the author, with time previously stipulated for agitation and centrifugation (5
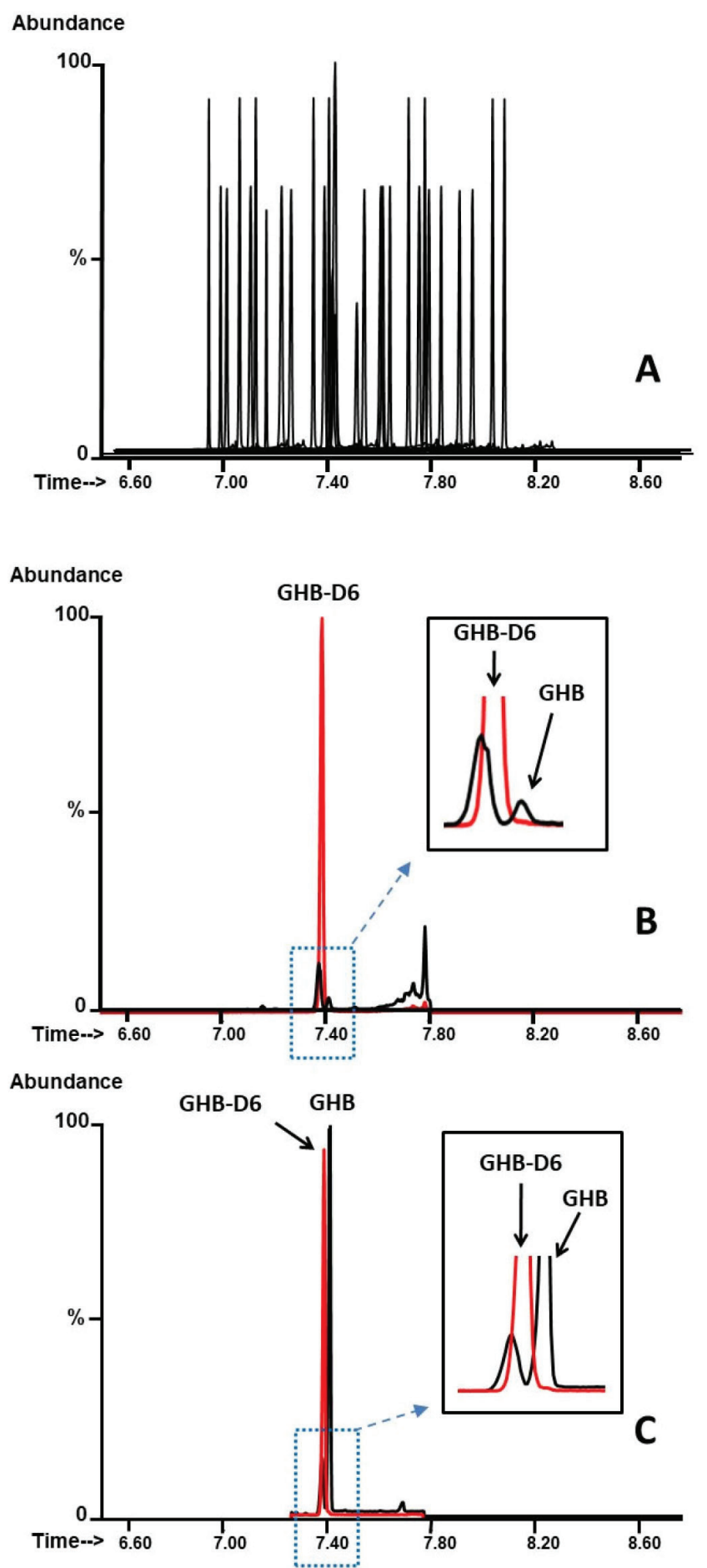

Figure 2. Chromatogram obtained through the analysis of GHB in urine samples according the purposed methodology. (A) Blank urine with addition of $10 \mu \mathrm{g} \mathrm{mL} \mathrm{L}^{-1} \mathrm{GHB}-\mathrm{D} 6$ in SCAN mode; (B) Blank urine with addition of $10 \mu \mathrm{g} \mathrm{mL} L^{-1} \mathrm{GHB}-D 6$ in SIM mode; (C) Blank urine with addition of $10 \mu \mathrm{g} \mathrm{mL^{-1 }}$ GHB-D6 and GHB respectively. Blank urine contains endogenous (basal) $G H B$

minutes), derivatization (5 minutes) and posterior chromatographic analysis (16 minutes). However, the developed procedure in the present work used only 10 seconds of agitation followed by 1 minute of centrifugation and 10 minutes of reaction with BSTFA $+1 \%$ TMCS. The complete chromatographic runtime was 13 minutes, which is faster when compared to others in the literature with a full validation. LOQ values $\left(0.50 \mu \mathrm{g} \mathrm{mL}^{-1}\right)$ is noteworthy, which is 20 times less than the 
Table 2. Comparison of GHB methods for urine samples by GC-MS

\begin{tabular}{|c|c|c|c|c|}
\hline Extraction procedure & Derivatization & Analysis time (minutes) & Linear Range ( $\left.\mu \mathrm{g} \mathrm{mL}^{-1}\right)$ & Reference \\
\hline$L L E$ & $B S T F A+1 \%$ TMCS & 23 & $0.5-20 *$ & purposed method \\
\hline LLE & BSTFA + $1 \%$ TMCS & 26 & $0.5-40$ & Busardò et al., 2014 ${ }^{33}$ \\
\hline LLE & $\mathrm{BSTFA}+1 \%$ TMCS & 32 & $1-100$ & Kütting et al., $2019^{25}$ \\
\hline SPME & Hexyl-chloroformate/pyridine & 33 & $0.05-20$ & Brown et al., $2007^{44}$ \\
\hline LLE & BSTFA + $1 \%$ TMCS & 35 & $5-500$ & Hassan \& Cooper, $2015^{45}$ \\
\hline LLE & BSTFA $+1 \%$ TMCS & 38 & $2-12$ & Andresen et al., $2010^{42}$ \\
\hline Headspace-Trap & GBL conversion & 40 & $5-1000$ & LeBeau et al., $2000^{15}$ \\
\hline LLE & GBL conversion & 46 & $2-200$ & Ferrara et al., $1993^{14}$ \\
\hline LLE & BSTFA $+1 \%$ TMCS & 46 & $20-500$ & Aromatario et al., $2012^{46}$ \\
\hline LLE & $\mathrm{BSTFA}+1 \%$ TMCS & 49 & $0.01-30$ & Shima et al., $2009^{38}$ \\
\hline Headspace-SPME & GBL conversion & 50 & $1-100$ & Frison et al., $2000^{47}$ \\
\hline LLE & BSTFA $+1 \%$ TMCS & 51 & $1-200$ & Kintz et al., $2005^{48}$ \\
\hline LLE & $\mathrm{BSFTA}+1 \% \mathrm{TMCS}$ & 51 & $1-200$ & Jamey et al., $2016^{49}$ \\
\hline SPE & $\mathrm{BSFTA}+1 \%$ TMCS & 51 & $1-100$ & Kim et al., $2019^{26}$ \\
\hline LLE & BSFTA $+1 \%$ TMCS & 52 & $1-100$ & Kietzerow et al., $2020^{27}$ \\
\hline LLE & BSFTA $+1 \%$ TMCS & 55 & $0.2-20$ & Elian, $2000^{29}$ \\
\hline Headspace-Trap & DMS/TBA-HSO4 & 56 & $5-150$ & Ingels et al., $2013^{50}$ \\
\hline LLE & $\mathrm{BSFTA}+1 \% \mathrm{TMCS}$ & 60 & $1-200$ & Villain et al., $2003^{19}$ \\
\hline LLE & $\mathrm{BSFTA}+1 \% \mathrm{TMCS}$ & 76 & $0,1-5$ & Crookes et al., 2004²0 \\
\hline LLE & GBL conversion & 83 & $0.01-100$ & Braislford et al., $2010^{39}$ \\
\hline SPME & BSFTA & 111 & $1.4-55$ & Arnoldi et al., $2018^{24}$ \\
\hline SPE & $\mathrm{BSFTA}+1 \%$ TMCS & 121 & $5-50$ & Adamowicz e Kala, $2010^{22}$ \\
\hline
\end{tabular}

Analysis time consider all steps for GHB determination per sample. BSTFA, N-O-Bis(trimethylsilyl)trifluoroacetamide; TMCS, trimethylchlorosilane; DMS, Dimethyl sulfate; TBA, tributylamine; LLE, liquid-liquid extraction; SPE, solid phase extraction; SPME, solid phase microextraction. *Dilution integrity was successfully performed considering the concentration of $50 \mu \mathrm{g} \mathrm{mL}{ }^{-1}$.

cut-off established by UNODC and SOFT., ${ }^{9,34}$ So, the purpose method allows endogenous GHB determination when necessary.

Several studies have evaluated the endogenous levels of GHB in a series of volunteers to determine a cut-off, differentiating endogenous from exogenous GHB. Cut-off value from $10 \mu \mathrm{g} \mathrm{mL}^{-1}$ has been reported in the literature ${ }^{20,35-39}$ and DFC guidelines..$^{34,35}$ However, cutoff value from $5 \mu \mathrm{g} \mathrm{mL} \mathrm{m}^{-140,41}$ and $6 \mu \mathrm{g} \mathrm{mL} \mathrm{m}^{-142}$ has already been reported as the best index to be used in DFC situations based on observations of endogenous values that are excreted in the urine.

However, the urinary concentration of GHB after ingesting a dose of this drug $\left(50 \mathrm{mg} \mathrm{kg}^{-1}\right)$ was determined previously. ${ }^{4}$ It was verified an extensive concentration range whose average was $3.8 \mu \mathrm{g} \mathrm{mL}^{-1}$ from 6 hours after GHB comsumption while urinary levels lower than $5 \mu \mathrm{g} \mathrm{mL}{ }^{-1}$ from 12 hours posterior GHB administration. So, this is an indication the detection period could be less than 12 hours after GHB administration. ${ }^{4}$ These results were corroborated by other findings, where the authors indicate GHB analysis in urine specimens within 3 days of sampling with the specimens stored at $-20{ }^{\circ} \mathrm{C}$ or $4{ }^{\circ} \mathrm{C}$ or add sodium fluoride (1-2\%) into the sample, which acts as an enzyme inhibitor. These procedures prevent in vitro GHB formation. ${ }^{43}$ Despite the discussions about the cut-off values to differentiate endogenous from exogenous GHB and its stability, the proposed method was able to unequivocally determine concentrations lower than the lowest value proposed $\left(\mathrm{LOQ}=0.5 \mu \mathrm{g} \mathrm{mL} \mathrm{mL}^{-1}\right.$ ).

Table 2 shows the scientific literature studies that deals with the analysis of GHB by GC-MS in urine samples and summarizes the total analysis time considering all steps, demonstrating that the purposed methodology adopted by the authors is more efficient in terms of time and handling. In this regard, the procedure developed to determine this analyte in this biological matrix has a working range compatible with lower concentrations proposed by other studies without the need for changes.

\section{CONCLUSIONS}

The purposed procedure to determine GHB in urine samples by GC-MS is simple and ultra fast, compatible with any toxicology laboratory with immediate application, being able to unequivocally identify the analyte, even in the lower concentrations proposed by other studies as well as the cut-off established by UNODC and SOFT $\left(10 \mu \mathrm{g} \mathrm{mL}^{-1}\right)$. Therefore, this methodology can be used for clinical analysis when endogenous GHB requires to be measured.

\section{ACKNOWLEDGEMENTS}

We thank CNPq for the doctoral scholarship for carrying out this study.

\section{REFERENCES}

1. LeBeau, M. A; Mozayani A; Drug-Facilitated Sexual Assault: A Forensic Handbook, Academic Press: San Diego, 2001.

2. Mari, F.; Politi, L.; Trignano, C.; Di Milia, M. G.; Di Padua, M.; Bertol, E.; The Journal of Forensic and Legal Medicine 2009, 16, 148.

3. Andresen, H.; Stimpfl, T.; Sprys, N.; Müller, A.; Dtsch. Arztebl. Int. 2008, 105, 599 . 
4. Haller, C.; Thai, D.; Jacob III, P.; Dyer, J. E.; J. Anal. Toxicol. 2006, 30, 360.

5. Elsohly, M. A.; Feng, S. In Benzodiazepines and GHB - Detection and Pharmacology; Salamone, S. J., ed.; Humana Press Inc.: New Jersey, 2001, pp. 33-49.

6. Drasbeck, K.; Christensen, J.; Jensen, K.; Acta. Neurol. Scand. 2006, $114,145$.

7. Busardò, F. P.; Jones, A. W.; Clin. Toxicol. (Phila) 2019, 57, 149.

8. Negrusz, A.; Gaensslen, R. E. In Clarke's Analytical Forensic Toxicology; Jickells, S., Negrusz, A., eds.; Pharmaceutical Press: Cambrigde, 2008, pp. 287-298.

9. https://www.unodc.org/unodc/en/scientists/guidelines-for-the-forensicanalysis-of-drugs-facilitating-sexual-assault-and-other-criminalacts_new.html\#: :text=Drug\%2Dfacilitated\%20sexual $\% 20$ assault $\% 20$ occurs,or $\% 20$ consent $\% 20$ to $\% 20$ such $\% 20$ acts, acessada em setembro 2020.

10. https://www.unodc.org/unodc/en/scientists/guidance-for-the-validationof-analytical-methodology-and-calibration-of-equipment.html, acessada em setembro 2020.

11. http://www.emea.europa.eu/docs/en_GB/document_library-Scientific_ guideline/2011/08/WC500109686.pdf, acessada em setembro 2020.

12. Elsohly, M. A.; Salamone, S. J.; J. Anal. Toxicol. 1999, 23, 141.

13. Lettieri, J. T.; Fung, H-L.; Biochem. Med. 1978, 20, 70.

14. Ferrara, S. D.; Tedeschi, L.; Frison, G.; Castagna, F.; Gallimberti, L.; Giorgetti, G. L.; Gessa, P. P. J. Pharm. Biomed. Anal. 1993, 11, 483.

15. LeBeau, M. A.; Montgomery, M. A.; Miller, M. L.; Burneister, S. G.; J. Anal. Toxicol. 2000, 24, 421.

16. Couper, F. J.; Logan, B. K.; J. Anal. Toxicol. 2000, $24,1$.

17. Elian, A. A.; Forensic Sci. Int. 2001, 122, 43.

18. Marsol-Vall, A.; Balcells, M.; Eras, J.; Canela-Garayoa, R.; Food Chem. 2016, 204, 210

19. Villain, M.; Cirimele, V.; Ludes, B.; Kintz, P.; J. Chromatogr. B 2003, $792,83$.

20. Crookes, C. E.; Faulds, M. C.; Forrest, A. R.; Galloway, J. H.; J. Anal. Toxicol. 2004, 28, 644 .

21. Paolli, G.; Bell, S.; J. Anal. Toxicol. 2008, 32, 298

22. Adamowicz, P.; Kala, M.; Forensic Sci. Int. 2010, 198, 39.

23. Paul, R.; Tsanaclis, L.; Kingston, R.; Berry, A.; Guwy, A.; Drug Test Anal. 2011, 3, 201.

24. Arnoldi, S.; Roda, G.; Argo, A.; Casagni, F.; Farè, F.; Visconti, G. L.; Dei Cas, M.; Gambaro V.; Journal of Forensic Sciences \& Criminal Investigation 2018, $2,1$.

25. Kütting, T.; Krämer, M.; Wolfgang, B.; Burkhard, M.; Cornelius, H.; Forensic Sci. Int. 2019, 299, 34
26. Kim, H.; Lee, D-H.; Go, A.; Park, M.; Choe, S.; In, S.; Kim, E.; Lee, H.; Shin, K-H.; Han, E. Int. J. Legal Med. 2019, 133,1785.

27. Kietzerow, J.; Otto, B.; Wilke, N.; Rohde, H.; Iwersen-Bergmann, S.; Andresen-Streichert, H.; Int. J. Legal Med. 2020, 134, 205.

28. Harris, D. C.; Quantitative Chemical Analysis; Harris, D. C., eds.; $9^{\text {th }}$ ed., W.H. Freeman and Co.: New York, 2016, pp. 568-569.

29. Elian, A. A.; Forensic Sci. Int. 2000, 109, 183.

30. Kimura, M.; Hasegawa, Y.; Nakagawa, K.; Kajita, M.; Watanabe, K.; Yamaguchi, S.; J. Chromatogr. B 2003, 792, 141.

31. Waszkielewicz, A.; Bojarski, A.; Pol. J. Pharmacol. 2004, 56, 43.

32. http://www.chemicalize.org, acessada em setembro 2020.

33. Busardò, F. P.; Bertol, E.; Vaiano, F.; Baglio, G.; Montana, A.; Barbera, N.; Zaami, S.; Romano G.; Forensic Sci. Int. 2014, 243, 144.

34. http://soft-tox.org/dfcc, acessado em setembro 2020

35. LeBeau, M. A.; Christenson, R. H.; Levine, B.; Darwin, W. D.; Huestis, M. A.; J. Anal. Toxicol. 2002, 26, 340.

36. Elliott, S. P.; Forensic Sci. Int. 2003, 133, 9.

37. Yeatman, D. T.; Reid, K. A.; J. Anal. Toxicol. 2003, 27, 40.

38. Shima, N.; Miki, A.; Kamata, T.; Katagi, M.; Tsuchihasi, H.; Forensic Sci. Int. 2005, 149, 171.

39. Braislford, A. D.; Cowan, D. A.; Kicman, A. T.; J. Anal. Toxicol. 2010, $34,555$.

40. Elian, A. A.; Forensic Sci. Int. 2002, 128, 120

41. LeBeau, M. A.; Montgomery, M. A.; Morris-Kukoski, C.; Schaff, J. E.; Deakin, A.; Levine, B.; J. Anal. Toxicol. 2006, 30, 98.

42. Andresen, H.; Sprys, N.; Schmoldt, A.; Mueller, A.; Iwersen- Bergmann. S.; Forensic Sci. Int. 2010, 200, 93

43. Busardò, F. P.; Zaami, S.; Baglio, G.; Indorato, F.; Montana, A.; Giarratana, N.; Kyriakou, C.; Marinelli, E.; Romano, G. Eur. Rev. Med. Pharmacol. Sci. 2015, 19, 4187.

44. Brown, S. D.; Rhodes, D. J.; Pritchard, B. J.; Forensic Sci. Int. 2007, $171,142$.

45. Hassan, H. M.; Cooper, G. A. A.; The Arab Journal of Forensic Sciences \& Forensic Medicine 2015, 1, 201.

46. Aromatario, M.; Bottoni, E.; Santoni, M.; Ciallella, C.; Forensic Sci. Int. 2012, 223, e38

47. Frison, G.; Tedeschi, L.; Maietti, S.; Ferrara, S. D.; Rapid Commun. Mass Spectrom. 2000, 14, 2401.

48. Kintz, P.; Villain, M.; Péllissier, A-L.; Cirimele, V.; Leonetti, G.; J. Anal. Toxicol. 2005, 29, 582

49. Jamey, C.; Kintz, P.; Martrille, L.; J Anal. Toxicol. 2016, 40, 546.

50. Ingels, A-S.; Neels, H.; Lambert, W. E.; Stove, C. P.; J. Chromatogr. A 2013, 1296, 84 